\title{
Conference Paper \\ Grid Code Requirements for Wind Power Integration in Europe
}

\author{
Constantinos Sourkounis and Pavlos Tourou \\ Institute for Power System Technology and Power Mechatronics, Ruhr-University Bochum, Germany \\ Correspondence should be addressed to Pavlos Tourou; tourou@enesys.rub.de
}

Received 11 December 2012; Accepted 14 March 2013

Academic Editors: Y. Al-Assaf, P. Demokritou, and A. Poullikkas

This Conference Paper is based on a presentation given by Pavlos Tourou at "Power Options for the Eastern Mediterranean Region" held from 19 November 2012 to 21 November 2012 in Limassol, Cyprus.

Copyright (C) 2013 C. Sourkounis and P. Tourou. This is an open access article distributed under the Creative Commons Attribution License, which permits unrestricted use, distribution, and reproduction in any medium, provided the original work is properly cited.

\begin{abstract}
As the capacity of wind power continues to increase globally, stricter requirements regarding grid connection of wind generators are introduced by system operators. The development of wind turbine technology is inevitably affected by the new grid codes, and wind power plants are expected to support the grid and provide ancillary services much like conventional power plants. The most demanding regulations are found in Europe where wind penetration levels are higher. This paper presents the main aspects of current grid code requirements for the integration of wind power in European countries and suggests performance characteristics in order to satisfy the most demanding requirements. The dynamic behavior of wind turbines with doubly fed induction generators is investigated and a solution for low voltage ride through compliance is presented.
\end{abstract}

\section{Introduction}

WIND power installations continue to increase worldwide, with a total installed capacity of $238 \mathrm{GW}$ by the end of 2011, which meets about $3 \%$ of the global electricity demand, and an expected capacity of $500 \mathrm{GW}$ by 2015 [1, 2]. In Europe, wind power generation is expected to contribute to EU's 2020 targets for reduction of carbon dioxide emissions by more than $30 \%$ and to supply at least $14 \%-16 \%$ of Europe's electricity [3]. The penetration of wind power in the electrical grids increases steadily in many European countries, with the highest percentage found in Denmark (28\%), a country that has recently set the ambitious target to produce $50 \%$ of its electricity from wind turbines by the end of 2020. In order to maintain reliable grid performance with increasing wind penetration, transmission system operators (TSOs) update their grid connection codes with specific requirements regarding the operation of wind generators and wind farms. In general, wind farms are expected to support the grid and to provide ancillary services much like conventional power plants (e.g., active power control, frequency regulation and dynamic voltage control, and low voltage ride through (LVRT)).
The requirements vary between countries and their severity usually depends on the wind power penetration level as well as on the robustness of the national or regional power network. Grid code requirements have been a drive for the development of wind turbine technology. Manufacturers in the wind energy sector are constantly trying to improve wind turbines, mainly in the area of wind turbine control and electrical system design, in order to meet the new grid code requirements. This can often imply higher costs, as more advanced power electronic designs and more complex control systems have to be utilized.

This paper discusses the influence of wind power on the operation of existing power systems and presents the main aspects of the latest grid code requirements for the integration of wind power in several European countries. The different requirements are analyzed and compared, and the most demanding are highlighted. The ability of different wind turbine technologies to meet these requirements is also discussed. The low voltage ride through, one of the most important requirements for the dynamic performance of wind turbines during network failures, is considered in detail. Simulation studies are conducted to study the behavior of wind turbines equipped with doubly-fed induction 
generators (DFIGs) during severe voltage dips caused by grid faults. Control strategies and hardware that improve the LVRT capability of the wind turbines during the fault are presented.

\section{Frequency and Voltage Operating Range}

2.1. Importance for Power System Operation. The power system frequency is an indication of the balance between power generation and load consumption. Any deviation from the planned production or consumption moves the system frequency away from its nominal value. In the case of a sudden increase in the load, the frequency of the produced voltage decreases and it is restored back to the nominal when power production is increased by primary control. Underfrequency can also occur as a result of an unexpected loss of generation units. On the other hand, over-frequency can occur with a sudden decrease in load or an unexpected increase in generation (e.g., wind gusts) [4].

Grid codes require that wind farms must be capable of operating continuously within the voltage and frequency variation limits encountered in normal operating conditions. In addition, they should remain in operation in case of frequency deviations outside the normal operating limits for a specified time and in some cases with a specific active power output. By having the ability to remain connected to the grid for a wider frequency range, wind farms support the system during abnormal operating conditions and allow for a fast system frequency restoration. Wind turbines must be designed appropriately, as abnormal frequencies can overheat generator windings, degrade insulation material, and damage power electronic devices.

2.2. Grid Code Requirements. The frequency ranges required by the various grid codes are presented in Figure 1. In the green frequency ranges, the wind turbines must remain connected and operate continuously at full power output. In the white ranges, they must remain connected at least for the minimum time specified, usually at a lower power output, in order to support the grid during frequency restoration. In many cases the active power reduction must be controlled proportionally with the frequency deviation from the nominal. In the extreme grey frequency ranges, wind turbines are allowed to disconnect from the grid. The active power requirements at different frequencies, if specified in the grid code, are also shown in Figure 1.

2.3. Comparison and Capability to Fulfill All Requirements. Wind turbines are now required to remain connected in the case of large frequency deviations, with the most extreme frequencies being $47 \mathrm{~Hz}$ and $53 \mathrm{~Hz}$. As the frequency deviation increases, the minimum connection time and minimum active power conditions are relaxed. In the case of underfrequencies wind turbines must remain connected to the grid for longer periods before they are allowed to trip. The largest frequency ranges of mandatory continuous operation, in which the wind turbines must never trip, are seen in the UK, Romania $(47.5 \mathrm{~Hz}-52 \mathrm{~Hz})$, and Italy $(47.5 \mathrm{~Hz}-51.5)$.
Large frequency ranges are expected in isolated systems with weak interconnections where the system stability is more vulnerable to disturbances compared to large interconnected systems (e.g., UCTE).

The most extreme requirements, taking also into account the voltage range level at which the frequency range is required, were combined to produce the frequency-voltage profile shown in Figure 2. If a wind turbine has the capability to operate within the area shown in Figure 2, then it can meet all the different requirements specified in the European grid codes.

\section{Active Power Control}

3.1. Importance for Power System Operation. Active power control is the ability of wind power plants to regulate their active power output to a defined level and at a defined ramp rate (e.g., in the case of active power curtailment requests by TSOs). These requirements aim to ensure a stable frequency in the system, to prevent overloading of transmission lines and to minimize the effect of the dynamic operation of wind turbines on the grid (e.g.) during extreme wind conditions, at startup/shutdown).

The ability of wind turbines to control their active power is also important for transient stability during faults. If the power can be controlled effectively as soon as a fault occurs, the turbine can be prevented from overspeeding. Hence, the reactive power needed for remagnetization of the generators is less after the fault is cleared, which helps reestablishing the grid voltage. Often, active power generation is reduced temporarily by the control system during the low voltage period [4]. This allows the increase of reactive power generation without exceeding the rated current of the converters. After the fault period, a fast return to normal active power generation is essential to ensure the power balance and stability of the grid.

3.2. Grid Code Requirements. Most grid codes demand active power curtailment upon request from the network operator, at a specified set-point. This is done either by disconnecting wind turbines or by controlling the pitch angle of the blades in order to limit the power extracted from the wind. Some grid codes also impose limitations on the rate of change of active power, with maximum and minimum ramp-up and rampdown rates. These limitations aim to suppress large frequency fluctuations caused by extreme wind conditions and to avoid large voltage steps and in-rush currents during wind farm startup and shutdown.

3.3. Comparison and Capability to Fulfill All Requirements. The most demanding requirements for active power control are presented in Table 1 .

Under normal conditions many grid codes require a ramp-down rate of $<10 \%$ of $P_{N}$ per minute. The most demanding requirements of both ramp-up and ramp-down rates under normal conditions are in Denmark where wind farms must always be able to vary their active power ramprates in the range $10 \%-100 \%$ of $P_{N}$ per minute upon request. 


\begin{tabular}{|c|c|c|c|c|c|c|}
\hline \multirow[b]{2}{*}{53.5} & England and Wales & Nordic & Scotland & Romania & Ireland & Denmark \\
\hline & & \multirow{4}{*}{$\begin{array}{c}3 \mathrm{~min} \text {, power reduction } \\
\text { possible at any level }\end{array}$} & \multirow{3}{*}{$\begin{array}{l}\text { Disconnection } \\
\text { within } 1 \mathrm{~s}\end{array}$} & & & \\
\hline 53 & & & & & & \\
\hline $\begin{array}{r}52.5 \\
52\end{array}$ & & & & & & \\
\hline \multirow{3}{*}{ 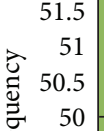 } & & & \multirow{3}{*}{$\begin{array}{l}2 \% \text { active power } \\
\text { reduction per } \mathrm{Hz}\end{array}$} & \multirow{3}{*}{$\begin{array}{l}\text { Continuous with } 20 \% \\
\text { max power losses }\end{array}$} & 60 min 2010 & $15 \mathrm{~min} 60 \%-100 \%$ of power \\
\hline & & 30 min, small $P$ reduction & & & OU & \\
\hline & & Continuous & & & & \\
\hline 49.5 & \multirow{4}{*}{$\begin{array}{l}\text { Max } 5 \% \text { linear } \\
\text { active power } \\
\text { reduction }\end{array}$} & Full power & \multirow{4}{*}{$\begin{array}{l}\text { Max 5\% linear } \\
\text { active power } \\
\text { reduction }\end{array}$} & \multirow{4}{*}{$\begin{array}{c}\text { Continuous-linear } \\
\text { power reduction }<20 \% \\
\text { proportional to } \\
\text { frequency deviation }\end{array}$} & \multirow{4}{*}{$60 \mathrm{~min}$} & \\
\hline 49 & & & & & & \\
\hline 48.5 & & $30 \mathrm{~min}$, linear reduction from & & & & 30 min $90 \%-100 \%$ power \\
\hline 48 & & $100 \%$ to $85 \%$ & & & & $3 \mathrm{~min}, 80 \%-100 \%$ power \\
\hline 47.5 & $20 \mathrm{~s}$ & & $20 \mathrm{~s}$ & 20 s, $80 \%$ power & $20 \mathrm{~s}$ & $20 \mathrm{~s}, 80 \%-100 \%$ power \\
\hline $\begin{array}{r}47 \\
46.5\end{array}$ & & & $\begin{array}{l}\text { Disconnection } \\
\text { within } 1 \mathrm{~s}\end{array}$ & & & \\
\hline
\end{tabular}

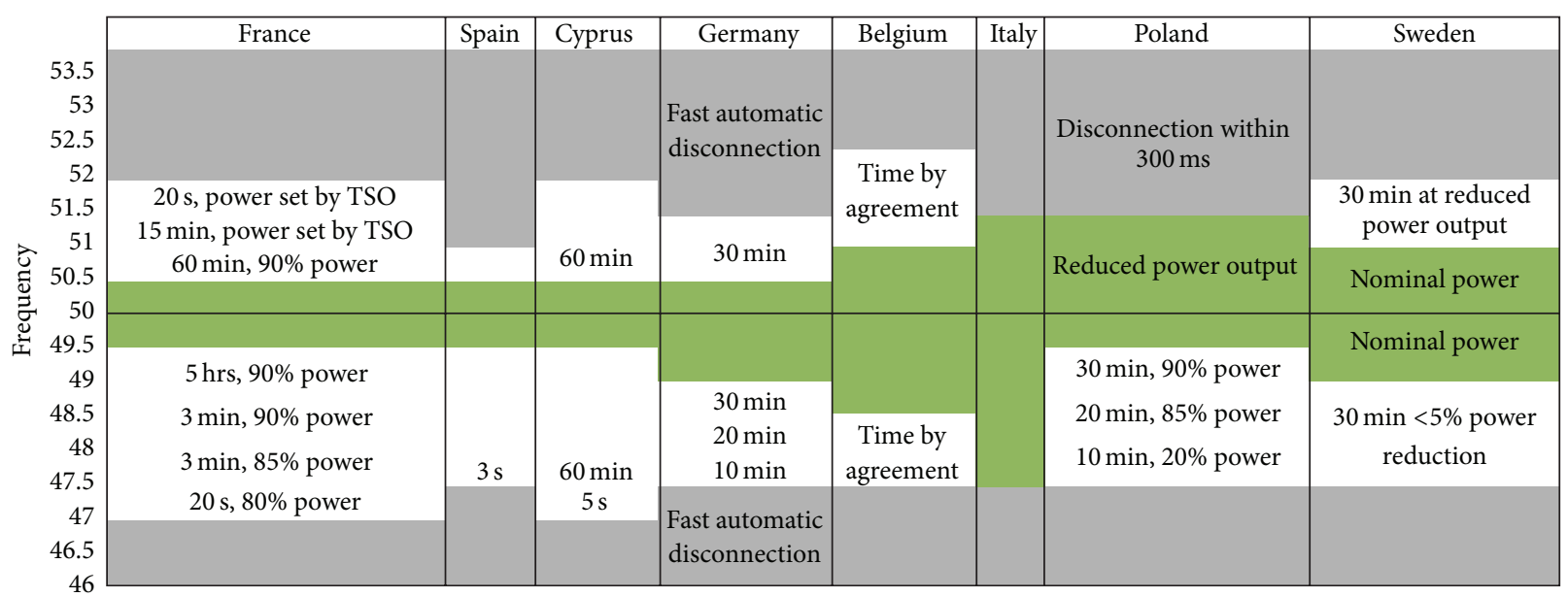

FIGURE 1: Required frequency range of operation in different grid codes.

TABLE 1: Active power requirements in different grid codes.

\begin{tabular}{lc}
\hline Condition & Active power ramp-rate \\
\hline Ramp-up rate range & $10-100 \%$ of $P_{N} / \mathrm{min}$ \\
Ramp-down rate range & $10-100 \%$ of $P_{N} / \mathrm{min}$ \\
Ramp-up rate after fault & $>90 \%$ of $P_{\mathrm{av}} /$ second \\
\hline
\end{tabular}

The fastest ramp-up rate of active power output after a fault back to the prefault value is that of Ireland and the UK $(>90 \%$ of $\left.P_{\mathrm{av}} / \mathrm{s}\right)$, where due to the isolated nature of their electrical grids the wind farms must provide fast active power support to assist in the grid voltage recovery.

In general, the most demanding requirements regarding active power control are found in the Danish grid code where wind farms must be equipped with and apply active power control functions with set-points and ramp-rates set by the system operator as shown in Figure 3. The "Delta" control function is particularly demanding, as the active power output of wind farms with capacity greater than $25 \mathrm{MW}$ must be constrained to a required constant value in proportion to the available active power. This reserve power can be used in fast grid frequency control, similar to the spinning reserves in conventional power plants.

\section{Reactive Power Control}

4.1. Importance for Power System Operation. The voltage levels in a power system must be maintained constant (within a very narrow range) because equipment of the utility and consumers are designed to operate at specific voltage levels. Recent adaptations to national grid codes demand from wind farms to contribute to voltage regulation in the system, as conventional power plants do. They must have the ability to generate or absorb reactive power in order to influence the voltage level at the point of common coupling (PCC). Under normal operation the voltage at the PCC can be increased by injecting reactive power to the grid and can be decreased by absorbing reacting power. Wind farms should have reactive power capabilities in order to support the PCC voltage during voltage fluctuations and to assist in balancing the reactive power demand in the grid. 


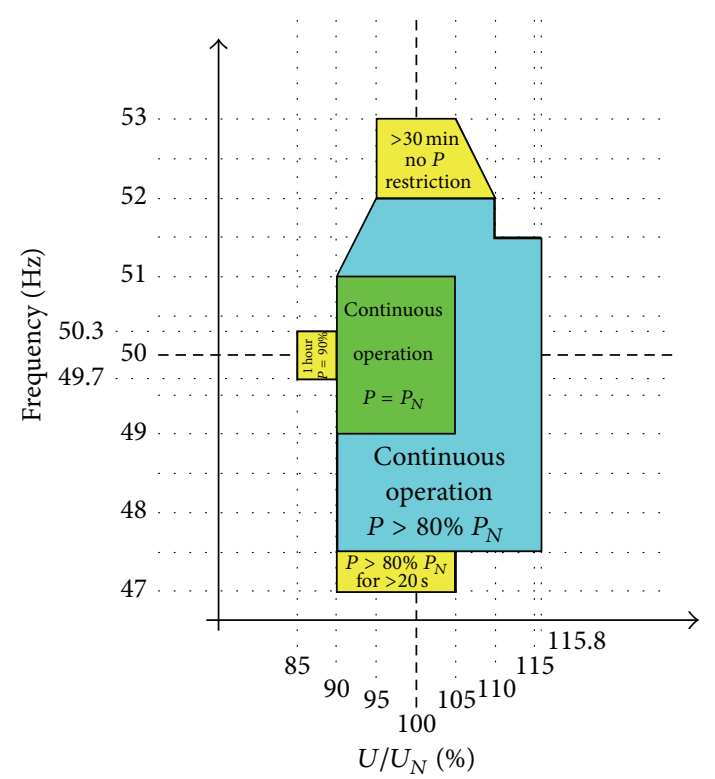

FIGURE 2: Most extreme requirements for wind farm operation at deviations from nominal grid voltage and frequency.

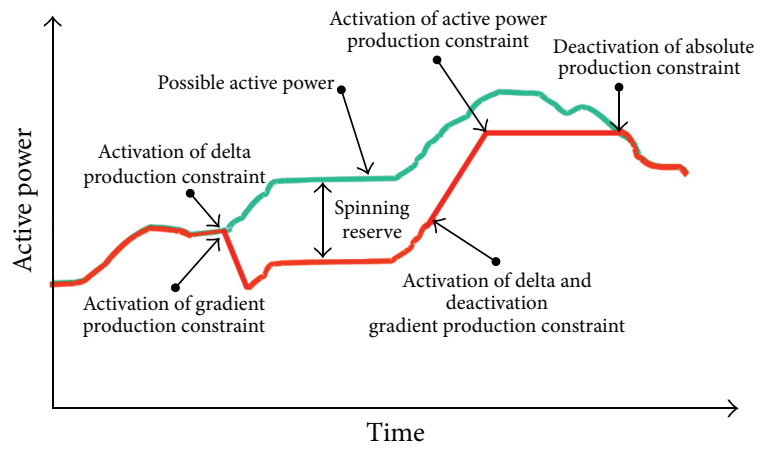

FIGURE 3: Active power control functions required in Denmark [4].

4.2. Grid Code Requirements. The reactive power requirements are usually expressed with $P-Q$ diagrams (available active power versus available reactive power). The required amount of reactive power compensation varies with different power system configurations. The effect of injected/absorbed reactive power on the PCC voltage level depends on the grid impedance, grid short-circuit capacity, as well as on any connected load near the point of connection [4]. The different reactive power requirements are summarized in Figure 4.

4.3. Comparison and Capability to Fulfill All Requirements. The widest ranges are found in Germany where one of the three variants must be chosen in agreement with the grid operator. In order to fulfill all grid code requirements in terms of reactive power capability, a wind turbine or farm must operate in the whole area shown in the $P / Q$ profile of Figure 5. At full active power the wind turbine must be capable of supplying reactive power in the range 0.41 p.u. inductive

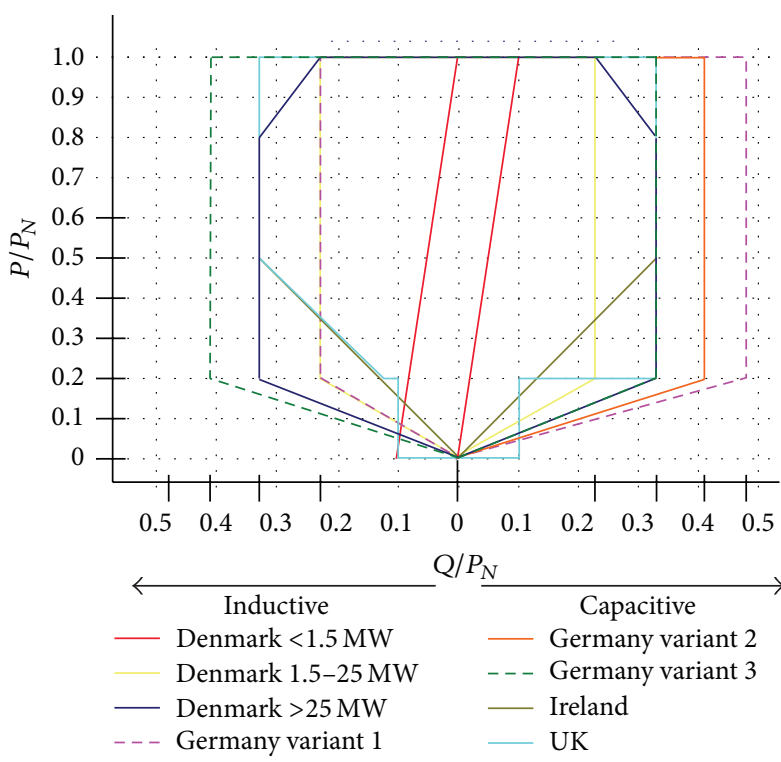

FIGURE 4: Reactive power requirements of various grid codes.

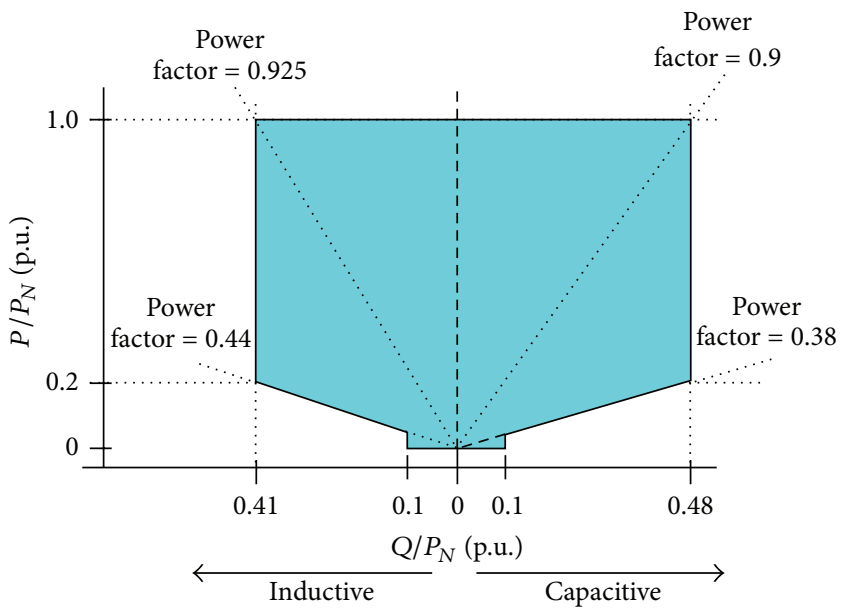

FIgURe 5: $P$-Q profile to satisfy all grid codes.

to 0.48 p.u. capacitive which corresponds to a power factor range 0.925 lagging to 0.9 leading. This reactive power range must be maintained with active power down to 0.2 p.u. and for lower active power output the reactive power can be decreased proportionally.

\section{Low Voltage Ride Through (LVRT)}

5.1. Importance for Power System Operation. The low voltage ride through is the most important requirement regarding wind farm operation that has been recently introduced in the grid codes. It is vital for a stable and reliable operation of power supply networks, especially in regions with high penetration of wind power generation. Faults in the grid can cause large voltage dips across wide regions and some generation units can be lost as a consequence. In the past, during grid disturbances and low grid voltages the wind 


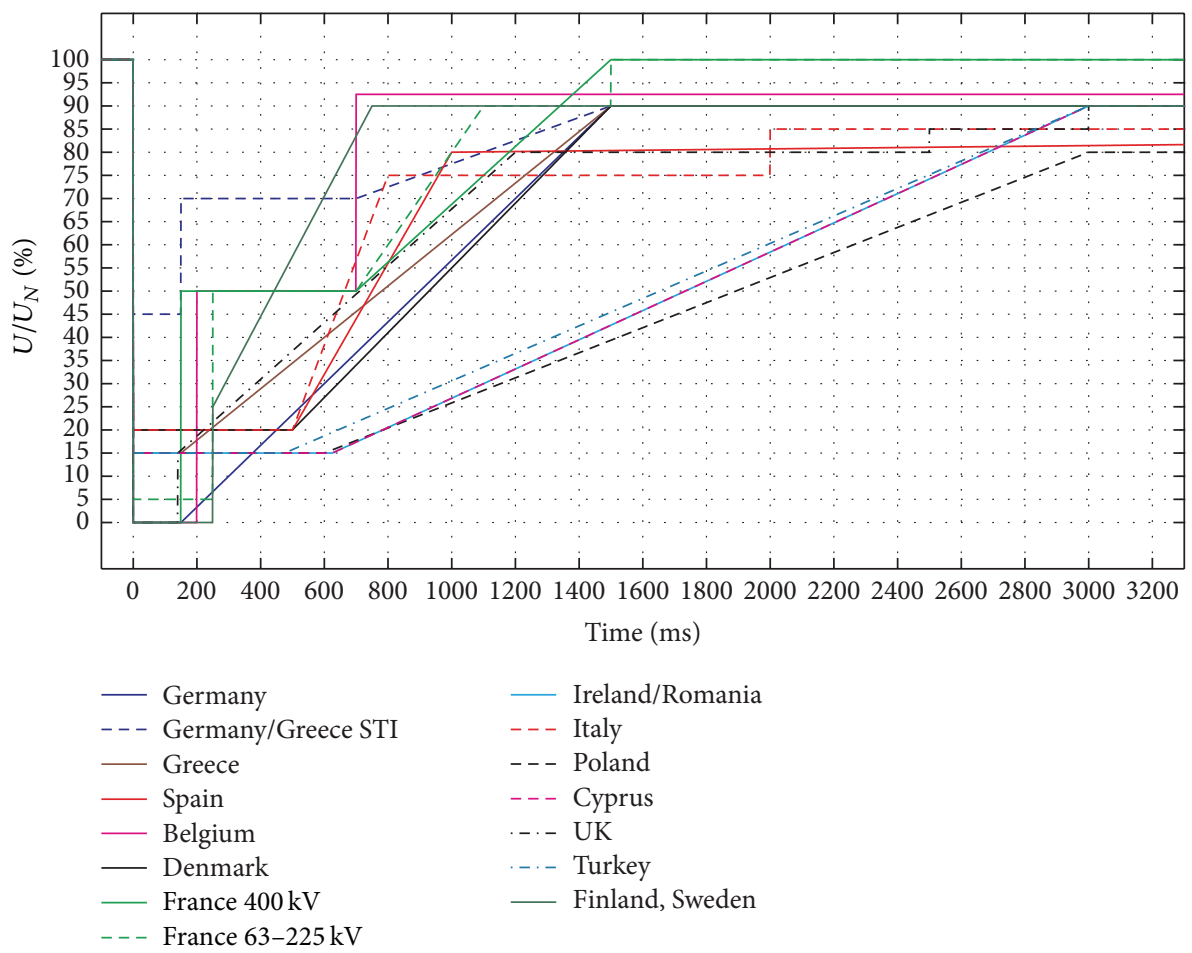

FIGURE 6: LVRT requirements in various grid codes.

turbines and farms were allowed to disconnect from the grid. But if there is a large amount of wind generation in the network, the simultaneous disconnection of wind generating units and farms can cause larger voltage depression and eventually collapse of voltage in the affected region. Furthermore, the additional loss of power generation as a result of the disconnection can cause a greater generation/consumption imbalance and thus drop in the system frequency in the wider region [5].

5.2. Grid Code Requirements. Recent grid codes require wind farms to remain connected and support the grid during and after a fault. They must withstand voltage dips of a certain percentage of the nominal voltage for the specified time durations, as shown in the LVRT voltage-time profiles of Figure 6. Disconnection is not allowed above the borderline. Below the borderline wind turbines are not required to contribute to the grid and they can be tripped by circuit breakers.

Furthermore, in some countries voltage control is required during the low voltage faults as shown in Figure 7. Wind farms must supply reactive current to the grid based on the depth of the voltage dip, in order to support the local voltage and thus limit the geographical low voltage area caused by the grid fault. During this low voltage period the active current can be decreased and priority should be given to the reactive current in order to back up the grid voltage. The German grid code asks for a constant of proportionality $k$ between the voltage deviation and the required reactive current that can be set in the range $k=0-10$ after an agreement with the network operator, with a default value $k=2$.

5.3. Comparison and Capability to Fulfill All Requirements. The most severe requirements for LVRT were combined to create the LVRT profile shown in Figure 8. Wind turbines and farms must remain connected to the grid above the solid line. Below the solid line and until 1.5 seconds after the start of the fault, wind turbines can disconnect only if they can resynchronize with the grid within 2 seconds. If voltage remains below $40 \%$ of the nominal after 1.5 seconds, wind turbine are allowed to disconnect unconditionally.

Regarding the contribution of the wind farms to grid voltage support, the German grid code is the most demanding as it can require rated reactive current at $20 \%$ voltage decrease with very fast step response characteristics (rise time $=30 \mathrm{~ms}$, transient time $=60 \mathrm{~ms}$ ). After fault clearance, the steepest increase of active power is found in the UK, according to which the active power must be increased to the prefault value with a rate equal to 1 p.u. per second. In the next sections, the response of DFIG-based wind turbines in the case of low voltage grid faults is analyzed, and their capability to meet the LVRT requirements is examined.

\section{LVRT Capability of DFIG-Based Wind Turbines with Doubly Fed Induction Generators}

Fixed-speed wind turbines with squirrel cage induction generators have a very limited LVRT capability. They are 


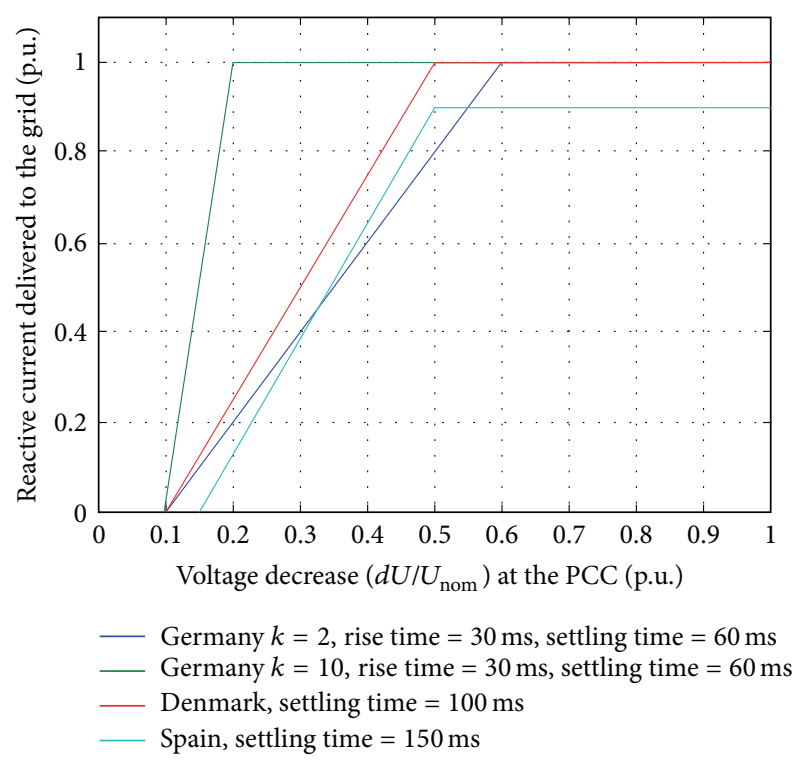

FIGURE 7: Reactive current requirements with grid voltage decrease.

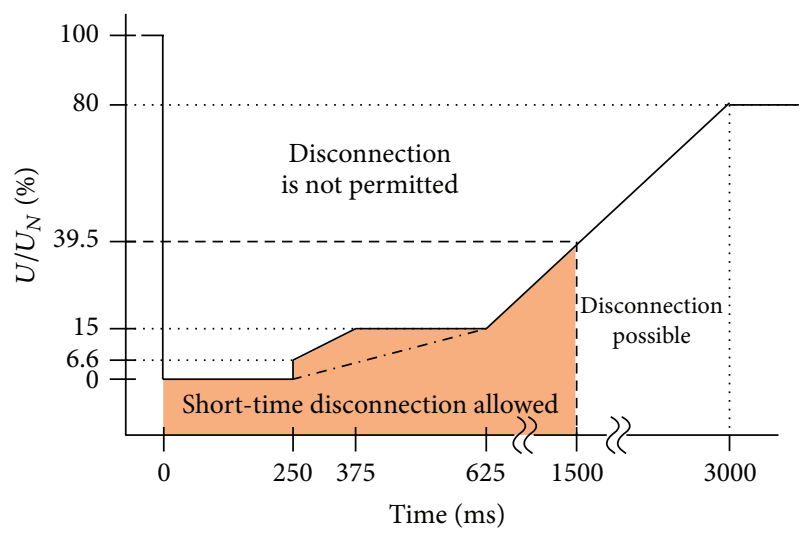

FIGURE 8: Fault ride through profile to satisfy all grid codes.

constantly absorbing reactive power from the grid for their magnetization. During low voltage faults they tend to overspeed and they can become unstable, suppressing further the grid voltage. The LVRT capability of wind farms with fixedspeed turbines can be improved by retrofitting reactive power compensation equipment such as static Var compensators (SVCs) and static synchronous compensators (STACOMs) [6]. Variable-speed wind turbines with full rated converters can ride through the faults without significant problems and they can deliver reactive power for voltage support. The LVRT capability of variable-speed wind turbines equipped with doubly-fed induction generators is studied in the following sections.

6.1. Doubly Fed Induction Generators. The doubly-fed induction generators (DFIGs) are currently the most widely used type of electrical generators for wind turbine systems in the Megawatt range [7]. The DFIG technology has proven to be an efficient and cost-effective solution for variable speed wind turbines. An important disadvantage of this type of generators is its behavior during significant voltage dips at their stator terminals. Before the introduction of LVRT requirements in the national grid codes, wind farms equipped with DFIG wind turbines were allowed to disconnect from the grid in the case of significant grid voltage deviations. In order for the wind turbines to remain connected and support the grid during low voltage periods, enhancements are required in the hardware and control of these wind turbines.

6.2. Description of a DFIG-Based Wind Turbine System. The wind rotor is in most cases connected to the rotor shaft of the generator through a gearbox that increases the rotational speed at the generator side as shown in Figure 9. The stator windings are directly connected to the grid. The rotor windings are connected to the grid through two voltage source converters connected back-to-back. This converter configuration decouples the rotor electrical frequency from the grid frequency, and as a result the rotor can have a variable speed, normally in a range $\pm 30 \%$ around the synchronous speed. Variable-speed wind turbines can harvest much more energy compared to fixed-speed wind turbines because depending on the wind speed, they can operate at the optimum rotational speed at which the aerodynamic efficiency of the wind rotor is maximum [8].

During normal operation the stator power flows from the stator to the grid, while the flow of rotor power over the DC-link is bidirectional; current flows from the grid to the rotor at undersynchronous speeds $\left(\mathbf{n}_{\mathbf{r}}<\mathbf{n}_{\mathbf{s}}\right)$ and in the opposite direction at oversynchronous speeds $\left(\mathbf{n}_{\mathbf{r}}>\mathbf{n}_{\mathbf{s}}\right)$. The maximum rotor power depends on the slip, and since the rotational speed range is limited, the rotor power is only a fraction of the stator power. This allows significant cost savings as the power electronic converters can be partially rated to only $25 \%-30 \%$ of the total power of the generator. Furthermore, the power efficiency is higher because there are lower switching and conduction losses in the power electronics due to the partial rating of the back-to-back converter.

6.3. Control System. The operation management controls the rotational speed of the wind turbine in order to capture maximum wind power [8]. It provides the active power reference to the rotor side converter (RSC) and the pitch angle to the pitch actuator system. Pitch control is used to limit the power output of the wind rotor in the case of very high wind speeds, by decreasing the aerodynamic efficiency of the rotor blades. Additionally the operation management limits the active power reference in the case of grid faults and after instructions from the network operator.

The RSC controller is responsible for providing decoupled control of the active and reactive power at the stator. The task of the grid side converter (GSC) controller is to keep the DC-link voltage constant, irrespective of the rotor power flow direction while maintaining unity power factor at the GSC terminals. A vector control approach is adopted for the RSC and GSC, and the resulting reference voltages are fed 


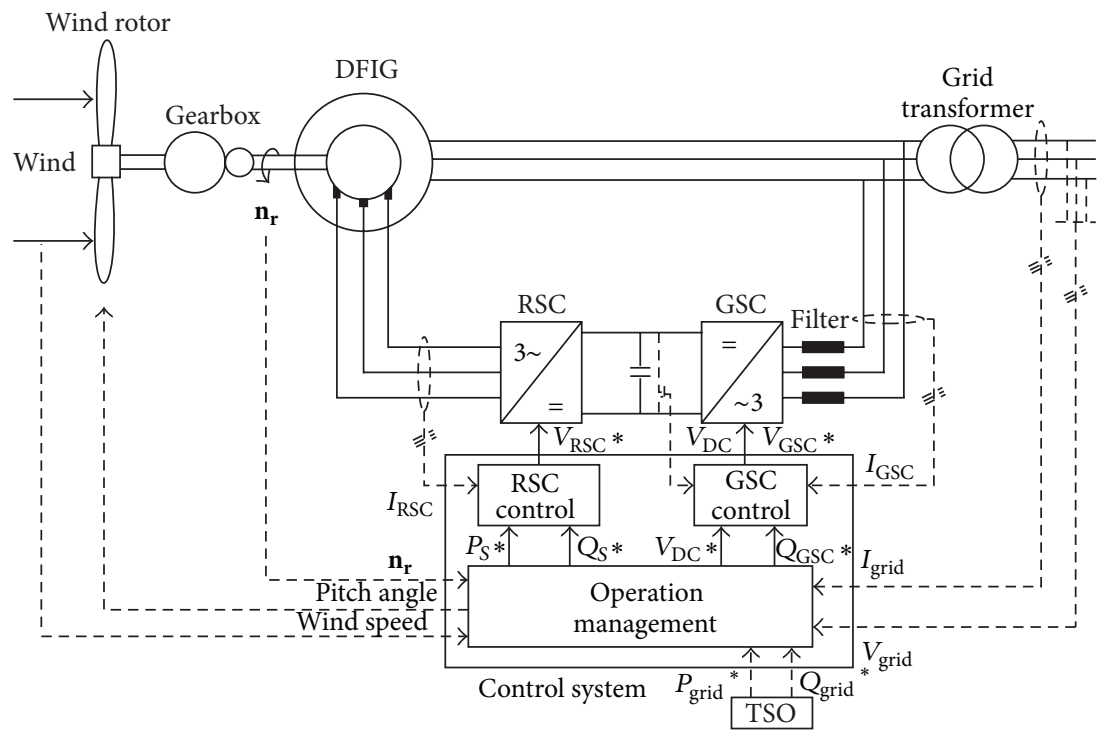

FIGURE 9: DFIG-based wind turbine system.

to space vector modulators to create the switching signal for the respective converters. By applying 3-phase voltages with the appropriate amplitude, phase, and frequency, the flow of currents and consequently the active and reactive power exchange with the grid at both the stator and the GSC terminals can be controlled.

\section{Investigations on the DFIG Response to Severe Grid Faults}

7.1. Response to Severe Voltage Dips. A detailed model of the DFIG-based wind turbine system was developed in Matlab/Simulink in order to investigate its behavior in the case of severe low voltage faults. In this paper, the worst case is considered: an instantaneous voltage drop down to zero volts for a time duration of $250 \mathrm{~ms}$ while the generator operates at maximum rotational speed and power output. The fault occurs at the grid-side of the transformer, and the voltage drop experienced by the wind turbine terminals is shown in Figure 10.

At the start of the fault very high transient currents are developed at the rotor and the RSC reaching 3 times the rated value of the converter. Furthermore, the voltage on the DC-link rises to 2.5 p.u. These effects arise due to the instantaneous collapse of the stator voltage. The stator flux space vector, which before the fault rotates synchronously with a magnitude proportional to the stator voltage, stops rotating and its magnitude decays exponentially with time. Similarly, DC stator currents with a decaying magnitude start to flow in the stator. Due to the electromagnetic coupling between the stator and the rotor circuits, the DC stator flux and currents induce a high frequency component in the rotor voltages, that is, superimposed on the normal voltage that has a low slip frequency. The magnitude of the induced rotor voltage is higher at the beginning of the fault and it can be greater than the stator voltage if the rotor speed at the time of the fault is oversynchronous [9]. The RSC, due to its partial rating, cannot produce such high voltages to match the induced rotor voltages, the control of current is lost, and very high currents result in the rotor and the RSC. These high currents flow into the DC-link, increasing the DClink voltage. The GSC cannot balance the DC-link voltage by dissipating this energy to the grid, because its power is limited due to the low residual voltage and its rated current. As result the DC-link voltage rises much higher than the rated voltage of the capacitor. Similarly, high rotor currents are also induced at the instantaneous return of the grid voltage. In this case the GSC can operate at its maximum power output, balancing the DC-link voltage faster.

These very high currents and the significant DC-link overvoltage are unacceptable because they can damage the DC-link capacitor and the power electronic switches of the RSC. In order to protect themselves against these effects during severe grid voltage faults, the DFIG-based wind turbines must disconnect from the grid, violating the LVRT grid code regulations. Appropriate countermeasures must be adopted in order to protect the sensitive devices of the wind turbine system and to meet the LVRT requirements.

7.2. Response to Voltage Dips with a LVRT-Enhanced System. In order to mitigate the effects of severe grid faults on the DFIG, the rating of the power electronic converters can be increased, so that it is possible to control the high transient currents at the beginning and end of the voltage dip. This solution is undesirable, as it eliminates the partial-rating advantage of the DFIG concept, increasing significantly the overall cost of the system. A more cost-effective solution is to use an active crowbar circuit between the rotor and the RSC as shown in Figure 11 [10]. This consists of a full-wave bridge rectifier, a power resistor, and an IGBT switch. During normal operation the switch is open. The switch can be activated on detection of rotor overcurrents or DC-link overvoltage in 

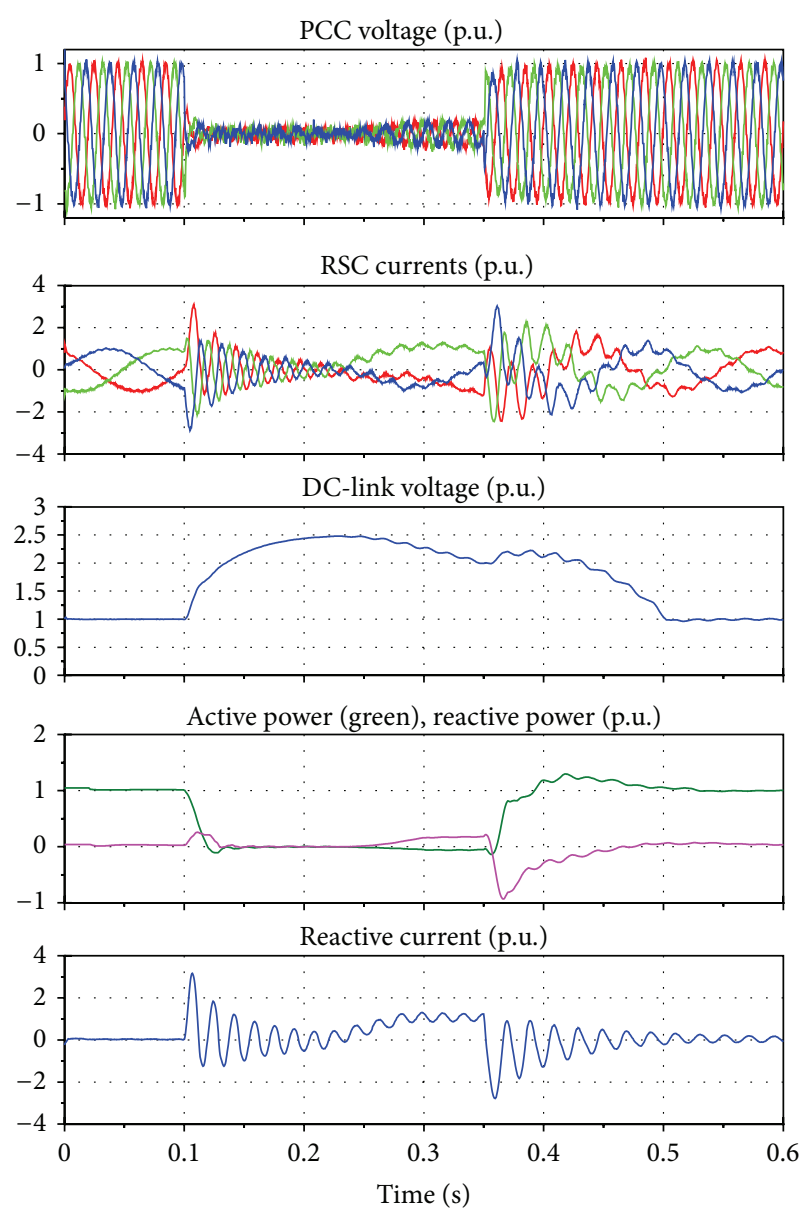

FIGURE 10: Response of a DFIG-based wind turbine during a $250 \mathrm{~ms}$ grid voltage dip.

order to redirect the rotor currents in the crowbar circuit, where the energy is dissipated in the resistor.

The behavior of the DFIG wind turbine equipped with a crowbar during a severe voltage dip is shown in Figure 12. The crowbar is activated with rotor overcurrent at the beginning and end of the voltage dip, and the high current peaks are successfully redirected away from the RSC. The DC-link voltage is limited below 1.3 p.u. during the fault. The crowbar remains connected to the rotor for about $50 \mathrm{~ms}$ to allow for the decay of the initial high transient currents. After this period the crowbar is disconnected and the RSC ramps up the reactive current to the rated value. A moderate increase in the local grid voltage is observed during the reactive current injection. During the fault the active power reference is kept to zero. The active power is increased back to the prefault value and the reactive power back to zero about $130 \mathrm{~ms}$ after clearance of the fault. In the case of longer voltage dips at higher residual voltage, sufficient active power must be delivered to the grid in combination with blade pitch control in order to prevent overspeeding of the wind rotor.

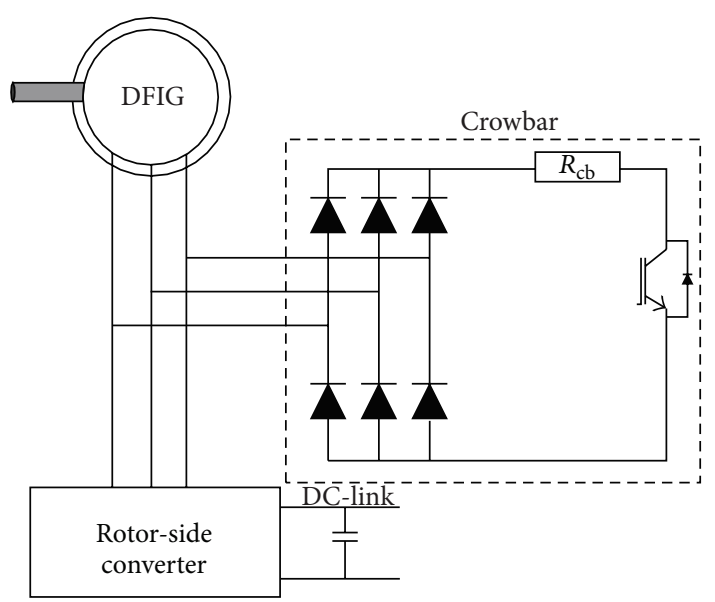

FIGURE 11: DFIG with an active crowbar circuit.
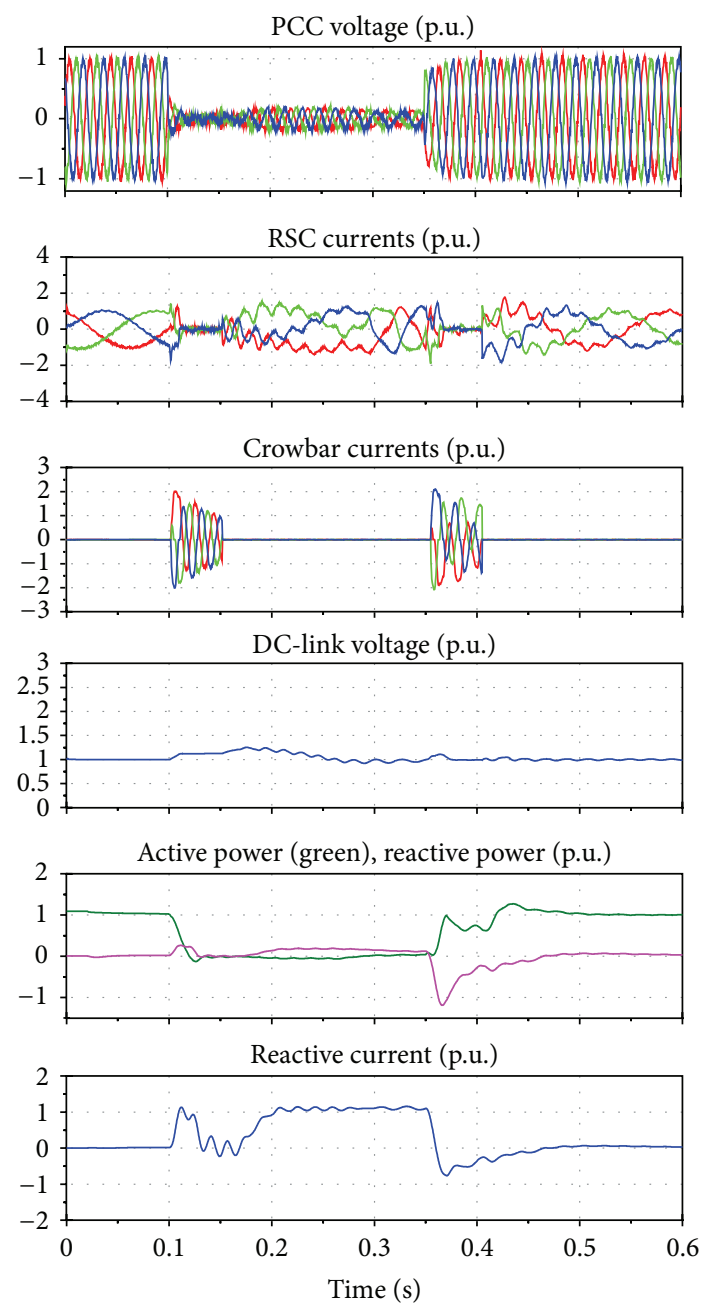

FIGURE 12: Response of a DFIG-based wind turbine with an active crowbar during a $250 \mathrm{~ms}$ grid voltage dip. 
7.3. Fulfilling the LVRT Requirements of Grid Codes. The DFIG wind turbines, enhanced with a crowbar and a dedicated control during the fault, can meet all the LVRT requirements found in the European grid codes. Simulation studies have shown that the wind turbines can "ride through" voltage dips down to zero voltage for $250 \mathrm{~ms}$. During the fault, they can provide voltage support by supplying rated reactive current to the grid and they can restore their active power very fast back to the prefault active power. In general, the crowbar solution can protect sensitive components of doubly fed induction generators and LVRT compliance can be achieved without the need for oversizing the expensive power electronic converters.

\section{Conclusion}

The main aspects of current grid code requirements regarding wind power integration in European grids have been presented. Performance characteristics in order to satisfy all the grid codes examined have also been suggested. As wind penetration increases, wind turbines and wind farms are expected to be more tolerant to abnormal conditions and to contribute to grid stability during normal operation, as well as during and after grid faults. The behavior of DFIGbased wind turbines during grid faults was investigated and a low cost solution for fulfilling the LVRT requirements was presented. Complying with grid code regulations is vital for grid stability and the improved wind turbine performance will allow for larger wind power penetration in electrical power grids.

\section{References}

[1] World Wind Energy Association, "World wind energy report 2011," May 2012, http://www.wwindea.org/webimages/WorldWindEnergyReport2011.pdf.

[2] Global Wind Energy Council, "Global Wind Report: Annual market update 2011," March 2012, http://gwec.net/wp-content/uploads/2012/06/Annual_report_2011_lowres.pdf.

[3] European Wind Energy Association, "Wind energy and EU climate policy," October 2011, http://www.ewea.org/filead$\mathrm{min} /$ ewea_documents/documents/publications/reports/20110 909_ClimateReport.pdf.

[4] T. Ackermann, Wind Power in Power Systems, John Wiley \& Sons, 2005.

[5] I. Erlich, W. Winter, and A. Dittrich, "Advanced grid requirements for the integration of wind turbines into the German transmission system," in Proceedings of the IEEE Power Engineering Society General Meeting (PES '06), p. 7, June 2006.

[6] M. Molinas, J. A. Suul, and T. Undeland, "Low voltage ride through of wind farms with cage generators: STATCOM versus SVC," IEEE Transactions on Power Electronics, vol. 23, no. 3, pp. 1104-1117, 2008.

[7] S. Müller, M. Deicke, and R. W. De Doncker, "Doubly fed induction generator systems for wind turbines," IEEE Industry Applications Magazine, vol. 8, no. 3, pp. 26-33, 2002.

[8] C. Sourkounis and B. Ni, "Influence of wind-energy-converter control methods on the output frequency components," IEEE Transactions on Industry Applications, vol. 45, no. 6, pp. 21162122, 2009.
[9] J. López, P. Sanchis, X. Roboam, and L. Marroyo, "Dynamic behavior of the doubly fed induction generator during threephase voltage dips," IEEE Transactions on Energy Conversion, vol. 22, no. 3, pp. 709-717, 2007.

[10] G. Pannell, D. J. Atkinson, and B. Zahawi, "Minimum-threshold crowbar for a fault-ride-through grid-code-compliant DFIG wind turbine," IEEE Transactions on Energy Conversion, vol. 25, no. 3, pp. 750-759, 2010. 

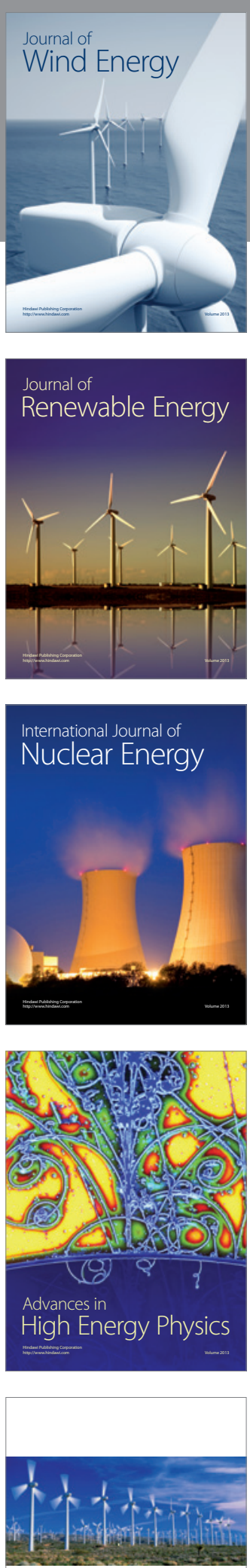

ISRN

Renewable Energy
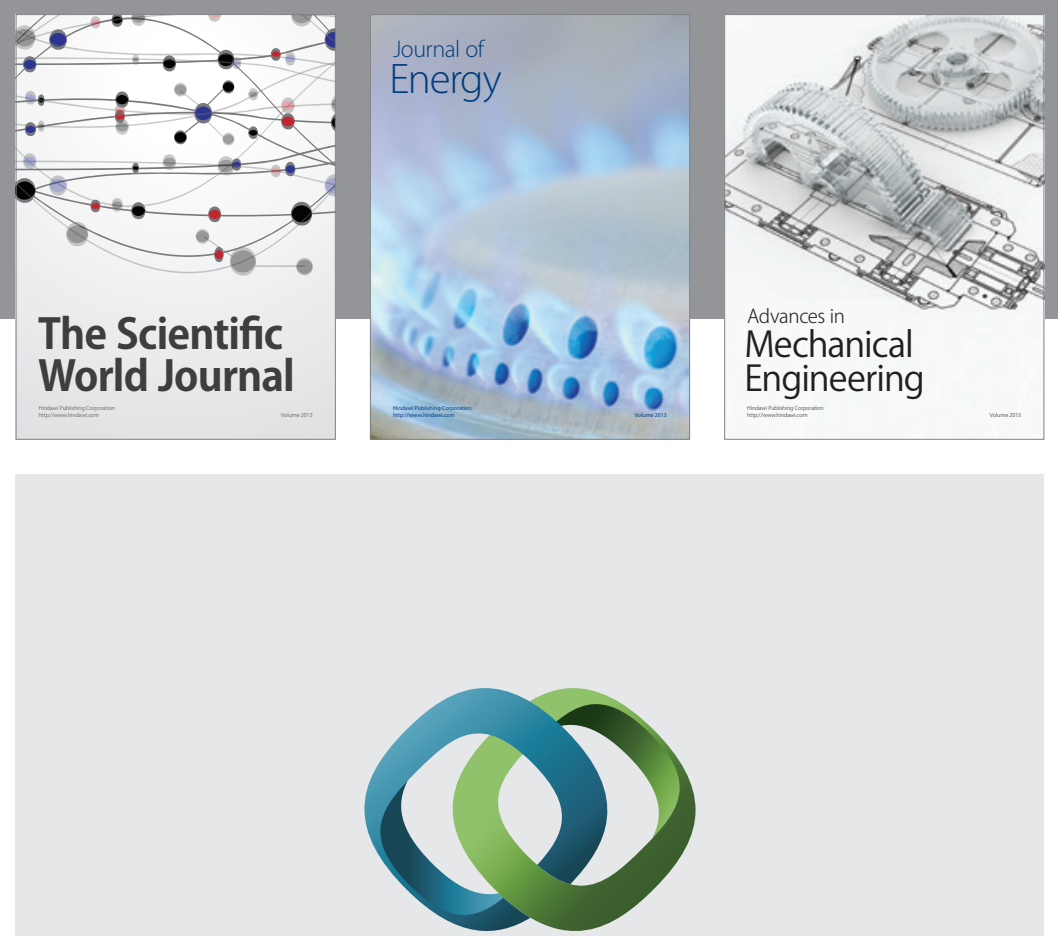

\section{Hindawi}

Submit your manuscripts at http://www.hindawi.com
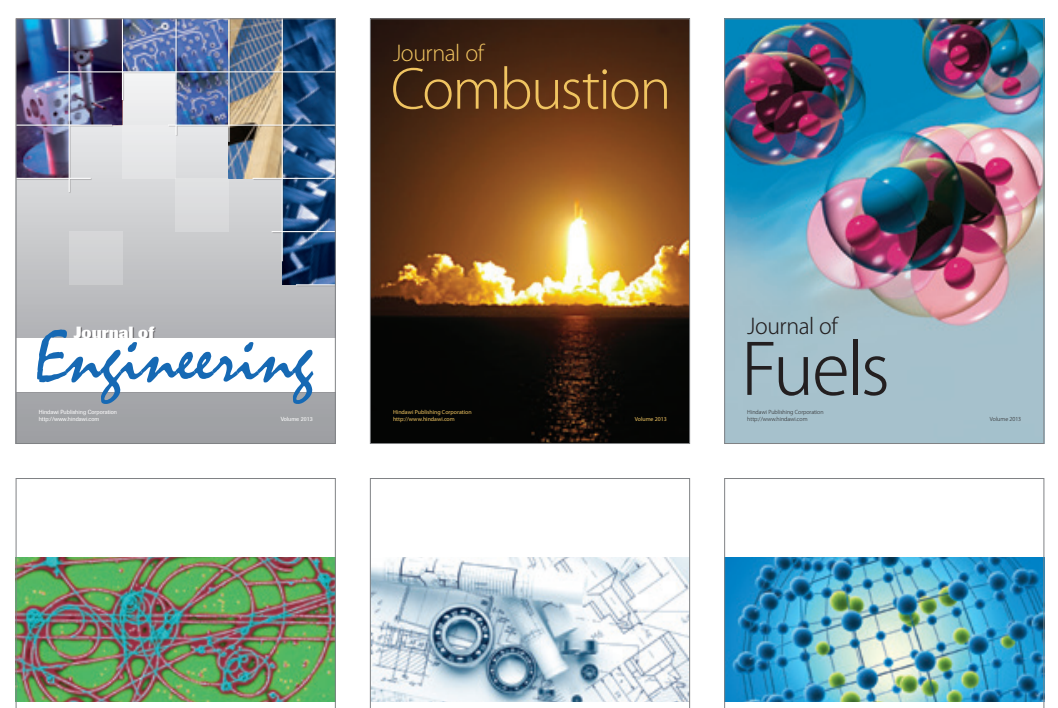

ISRN

High Energy Physics

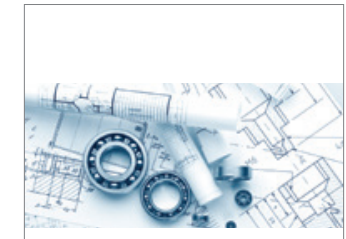

ISRN

Mechanical

Engineering

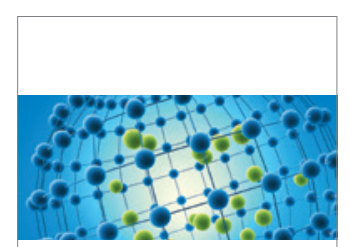

ISRN

Chemical

Engineering
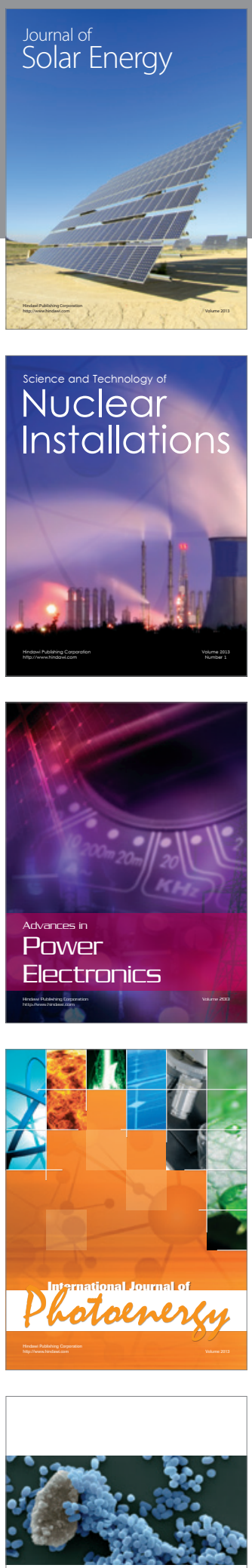

ISRN

Biotechnology 

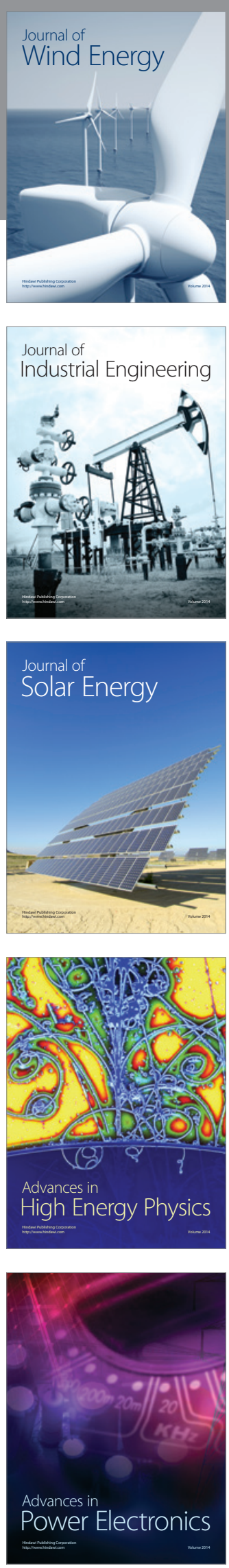
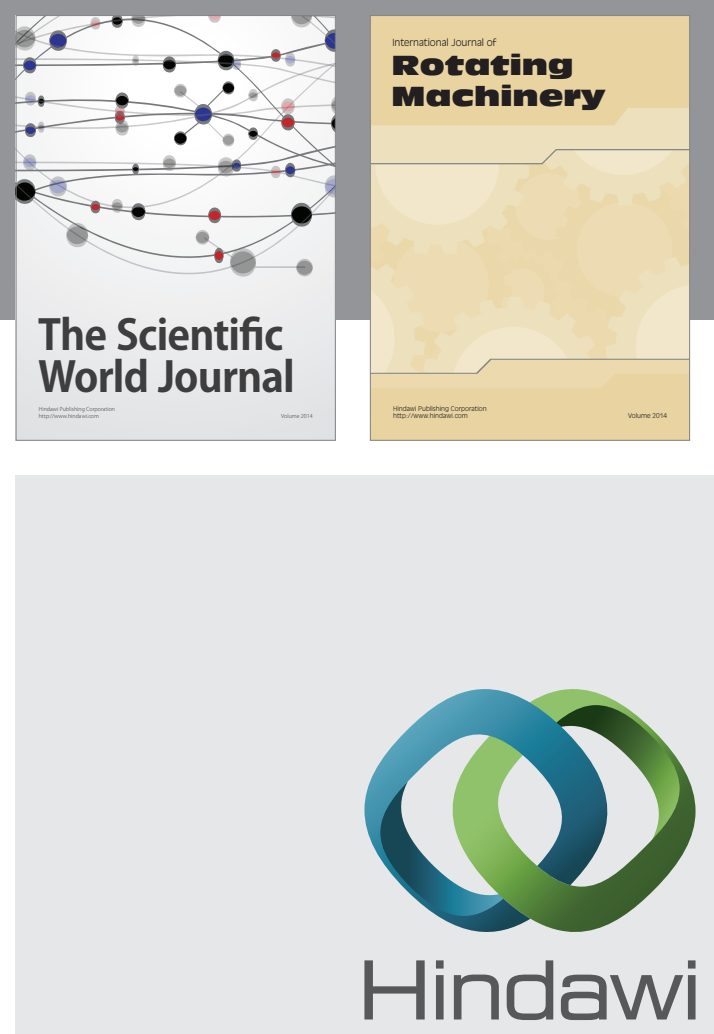

Submit your manuscripts at

http://www.hindawi.com
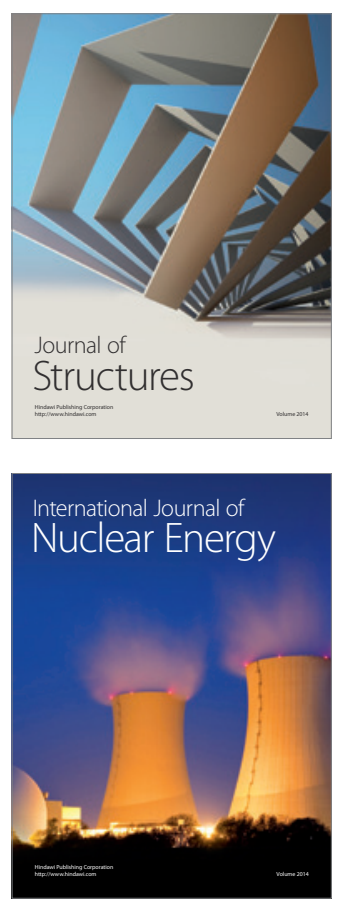
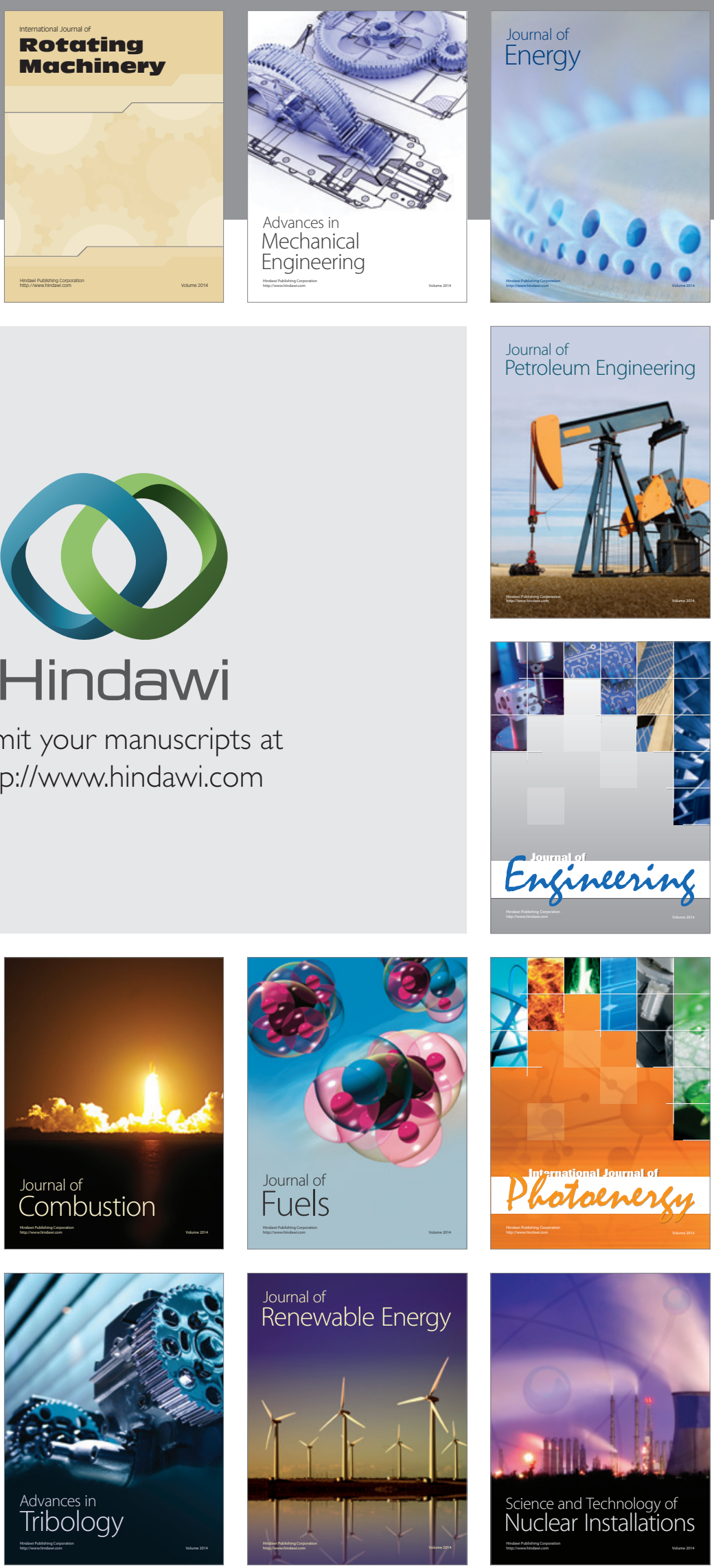